\title{
Correction to: Road Transportation Emissions in India: Adopting a 'Hub' and 'Spoke' Approach Towards Electric-Driven Decarbonization
}

\author{
Mahesh Sugathan
}

\section{Correction to:}

Chapter "Road Transportation Emissions in India:

Adopting a 'Hub' and 'Spoke' Approach Towards

Electric-Driven Decarbonization” in: T. Brewer (ed.),

Transportation Air Pollutants, Springer Briefs in Applied

Sciences and Technology,

https://doi.org/10.1007/978-3-030-59691-0_4

The original version of the book was published with incorrect mail

ID. The chapter Author's e-mail address have been updated as "msugathan.tradeprojects@gmail.com". The chapter and book have been updated with the changes. 